\title{
A study on the use of planarity for quick identification of potential landslide hazard
}

\author{
M. H. Baek ${ }^{1}$ and T. H. Kim ${ }^{2}$ \\ ${ }^{1}$ Department of Fire and Disaster Prevention, Major of Emergency Management, Kangwon National University, \\ 346 Hwangjo-gil, Dogaeeup, Samcheok, 245-905 Gangwon-do, Republic of Korea \\ ${ }^{2}$ National Disaster Management Institute, Ministry of Public Safety and Security, 136, Mapo-daero, Mapo-gu, \\ 121-719 Seoul, Republic of Korea
}

Correspondence to: T. H. Kim (taihoon@ualberta.ca)

Received: 2 September 2014 - Published in Nat. Hazards Earth Syst. Sci. Discuss.: 20 November 2014

Revised: 2 April 2015 - Accepted: 27 April 2015 - Published: 20 May 2015

\begin{abstract}
In this study we focused on identifying a geomorphological feature that controls the location of landslides. The representation of the feature is based on a highresolution digital elevation model derived from the airborne laser altimetry (LiDAR) and evaluated by the statistical analysis of axial orientation data. The main principle of this analysis is generating eigenvalues from axial orientation data and comparing them. The planarity, a ratio of eigenvalues, would tell the degree of irregularity on the ground surface based on their ratios. Results are compared to the recent landslide case in Korea in order to evaluate the feasibility of the proposed methodology in identifying the potential landslide hazard. The preliminary landslide hazard assessment based on the planarity analysis discriminates features between stable and unstable domain in the study area well, especially in the landslide initiation zones. Results also show it is beneficial to build the landslide hazard inventory mapping, especially where no information on historical records of landslides exists. By combining other physical procedures such as geotechnical monitoring, the landslide hazard assessment using geomorphological features promises a better understanding of landslides and their mechanisms and provides an enhanced methodology to evaluate their hazards and appropriate actions.
\end{abstract}

\section{Introduction}

Landslides, reflecting the geomorphological process of the natural landscape, become a threat only when they interfere with our societies (Pestrong, 1976). They annually cause losses of many lives and have enormous economic impacts. There is considerable attention paid to landslides since they usually cause significant casualties and property damage (Aleotti and Chowdhury, 1999). Increasing costs are closely related to the expansion of population and development in residential areas near slopes. Through urban expansions, cities transform their surrounding environments and produce new risks (UNDP, 2004). Constructing residences, industrial structures, transportation routes, and lifelines around the slopes may decrease their stability. Therefore, landslides became disastrous events and, in turn, disturb and affect the well-being of society. In developing countries, these impacts are even more severe (Schuster and Highland, 2007).

Once landslides occur, they usually leave features such as scarps, cracks, and displaced materials on the ground. Identifying these geomorphological features in order to determine the potential landslide hazard area would provide valuable information for assessing the landslide hazard. The identification of locations potentially susceptible to landslides is, however, a long-debated topic, and a large variety of methods have been proposed to map those areas (Soeters and van Westen, 1996; Guzzetti et al., 1999, and references therein). Although many studies proved that many explanatory variables have to be combined to obtain the best possible landslide susceptibility assessments (Nefeslioglu et al., 2011; 
Catani et al., 2013), sometimes a preliminary assessment is needed and a single terrain attribute easily derivable from digital elevation models (DEMs) could be used as an indicator for potential landslide areas.

A recent distinct development in this field is utilizing remote sensing technologies. For example, Kimura and Yamaguchi (2000) used a synthetic aperture radar interferometry (InSAR) with precipitation data for modeling landslide movements in northern Japan. They noted that the model powered by InSAR technology can account for the complex landslide movements showing either shallow or deep-seated landslide when ground surface measurements observed at the same location are difficult to recognize the overall movement mechanisms. Catani et al. (2005) also discussed the capability of the SAR interferometry technique for quantifying landform attributes. While InSAR technologies are focused on the recognition of dynamic behaviors of landslide movement mechanisms, the static quantification of landslide-controlled attributes is carried out by a high-resolution topographic information, which is obtained from LiDAR (Light Detection and Ranging) technique (Glenn et al., 2006). LiDAR can generate high-resolution models which differentiate distinct landslide features such as steep scarps at the top, fan shaped lobes at the toe, and an irregular hummocky topography between top and bottom. These features can be evaluated based on their evolution by natural processes over time. The landslide inventory mapping enhanced by the LiDAR-derived DEM can provide not only the exact boundary of previous landslides but also insight into the internal deformation of the landslide body (McKean and Roering, 2004). Other applications augmented by LiDAR-derived DEM, from detection to modeling and monitoring, are well described by Jaboyedoff et al. (2012). However, approaches to find these remnants of landslides have several limitations (Kim et al., 2012). Major issues are insufficient compilation of key features and changes of topography by other processes such as weathering. Implementing landslide hazard assessments with incomplete information would lead to erroneous decisions about ongoing and future developments of landslides (Kim, 2012).

In this study, therefore, we focus on identifying locations which are potentially susceptible to landslides using a geomorphological feature. For this scope, the work proposes the use of a measure of the irregularity in the terrain, defined by a statistical analysis of axial orientation data in a threedimensional space performed on a high-resolution DEM. Results are applied to identify locations of the recent landslide and are compared to other terrain attributes to find whether the proposed methodology assures the potential landslide hazard.

\section{Methodology}

Analyzing a terrain, whether rough or smooth, is an important part of landslide studies in which understanding a terrain is essential to the future development of landslides. Finding geomorphological features that are generated by landslides is the main purpose of landslide inventory mapping, which gathers information from various sources such as aerial photographs and archives. However, the limited time span and evolution of topography by natural processes may have restricted any meaningful progress using terrain attributes. Various approaches were examined to overcome these limitations (Glenn et al., 2006; Kaplan, 2006; Delacourt et al., 2007; Sappington et al., 2007; Schulz, 2007; van Den Eeckhaut et al., 2007; Teza et al., 2008; Grohmann et al., 2009).

One promising methodology describing geomorphological features is the statistical analysis of axial orientation data in a three-dimensional space. Obtained from the orientation tensor, they are useful to analyze the randomness in directional data on a sphere (Woodcock, 1977; Woodcock and Naylor, 1983).

Based on the spherical distribution of directional and nondirectional data, it is shown that typical characteristics of the spherical distribution are equivalent to the determination of eigenvalues and eigenvectors, especially of a symmetric 3 by 3 matrix which comprises direction cosines (Watson, 1966). When we consider $N$ points of the unit mass of $\left(l_{i}, m_{i}, n_{i}\right)$, where $N=1,2, \ldots, N$, and suppose that $\boldsymbol{u}$ is a true or preferred direction through the center of the sphere, the moment of inertia $I$ of the set of $N$ points of unit observation data about $\boldsymbol{u}$ can be described as follows (Watson, 1966):

$I=N-\boldsymbol{u}^{\prime} \mathbf{M} u=N-\sum_{j=1}^{3} \sum_{k=1}^{3} u_{j} \mathbf{M}_{j k} u_{k}$,

where $\mathbf{M}$ is an orientation matrix, a 3 by 3 matrix consisting of sums of the cross products of direction cosines of the unit mass $\left(l_{i}, m_{i}, n_{i}\right)$. It is given by

$\mathbf{M}=\left(\begin{array}{lll}\sum l_{i}^{2} & \sum l_{i} m_{i} & \sum l_{i} n_{i} \\ \sum m_{i} l_{i} & \sum m_{i}^{2} & \sum m_{i} n_{i} \\ \sum n_{i} l_{i} & \sum n_{i} m_{i} & \sum n_{i}^{2}\end{array}\right)$.

The eigenvalues of the orientation matrix are calculated from roots of the characteristic equation. Therefore

$\operatorname{det}(\mathbf{M}-\lambda \mathbf{I})=0$,

where det is the determinant of $\mathbf{M}$ and $\mathbf{I}$ is the identity matrix. Roots of the characteristic equation are eigenvalues, $\lambda_{i}$ $\left(i=1,2,3 ; \lambda_{1}>\lambda_{2}>\lambda_{3}\right)$, and corresponding vectors are eigenvectors, $\boldsymbol{v}_{i}(i=1,2,3)$. Three eigenvalues are always positive and added to $N$ while three eigenvectors are always perpendicular to each other (Watson, 1966). A normalized form of the eigenvalues can be obtained from dividing by the number of unit observation points, $N$ : 
Table 1. Types of the spherical distributions based on eigenvalues and eigenvectors of the orientation matrix M. The order of eigenvalues is $\lambda_{1}>\lambda_{2}>\lambda_{3} . R$ is the length of the resultant vector. Modified from Mardia (1972).

\begin{tabular}{|c|c|c|c|}
\hline \multicolumn{2}{|c|}{ Eigenvalue distribution } & Spherical distribution & Eigenvector distribution \\
\hline \multicolumn{2}{|c|}{$\lambda_{1} \simeq \lambda_{2} \simeq \lambda_{3}$} & Random & No preferred orientation \\
\hline \multirow{2}{*}{$\lambda_{1}>\lambda_{2}, \lambda_{3}$} & & $\begin{array}{l}\text { Unimodal if } R \text { is large } \\
\text { Bimodal otherwise }\end{array}$ & $\begin{array}{l}\text { Concentrated at one end of } v_{1} \\
\text { Concentrated at both ends of } v_{1}\end{array}$ \\
\hline & $\lambda_{2}$ & $\begin{array}{l}\text { Unipolar if } R \text { is large } \\
\text { Bipolar otherwise }\end{array}$ & Rotational symmetry about $\boldsymbol{v}_{1}$ \\
\hline$\lambda_{1}, \lambda_{2}>\lambda_{3}$ & $\begin{array}{l}\lambda_{1} \neq \lambda_{2} \\
\lambda_{1} \simeq \lambda_{2}\end{array}$ & $\begin{array}{l}\text { Girdle } \\
\text { Symmetric girdle }\end{array}$ & $\begin{array}{l}\text { Girdle plane containing } \boldsymbol{v}_{1} \text { and } \boldsymbol{v}_{2} \\
\text { Rotational symmetry about } \boldsymbol{v}_{3}\end{array}$ \\
\hline
\end{tabular}

$S_{j}=\frac{\lambda_{j}}{N}, j=1,2,3$

The determination of the typical distribution in eigenvalues and eigenvectors is dependent of the spherical location of the axial orientation data. Watson (1966) proposed two distinct distributions on a spherical surface: (a) a clustered distribution and (b) a girdle distribution, both of which are represented by the different magnitude and direction of eigenvalues and eigenvectors (Fig. 1). If the unit mass are clustered at both ends of the great circle in a sphere (Fig. 1a), indicating either uni- or bimodal distributions, the moment of inertia in Eq. (1) along this axis would be small and, therefore, large eigenvalue and eigenvector are induced from the small value of the moment of inertia. Two other small values of eigenvalue and eigenvector are comparable and located along the diameter of the great circle. Obviously fairly equal eigenvalues would represent no preferred direction which having the uniform distribution in observation data. For the clustered distribution, therefore, one large eigenvalue and other two small eigenvalues are usually observed.

A girdle distribution, where the unit mass is positioned around the great circle (Fig. 1b), would require the greatest moment of inertia, which leads to a minimum eigenvalue at the axis perpendicular to the great circle. The other two moments of inertia along the diameter of the great circle have the least values and they cause large eigenvalues and eigenvectors, both of which have similar values. The girdle distribution, therefore, is generally indicated by one small eigenvalue with two large eigenvalues. Detailed types of the spherical distributions based on eigenvalues and eigenvectors of the orientation matrix $\mathbf{M}$ are summarized in Table 1 .

The principle of the statistical analysis proposed by this study is to generate eigenvalues that represent typical values for the degree of irregularity. For more clear identification, we introduce one non-dimensional parameter, composing the ratio of eigenvalues (Woodcock, 1977; Woodcock and Naylor, 1983):

planarity $=\ln \left(\frac{S_{1}}{S_{2}}\right)$.

The planarity $(P)$, the natural logarithmic proportion of the eigenvalue $S_{1}$ relative to $S_{2}$, can be a good indicator in de-

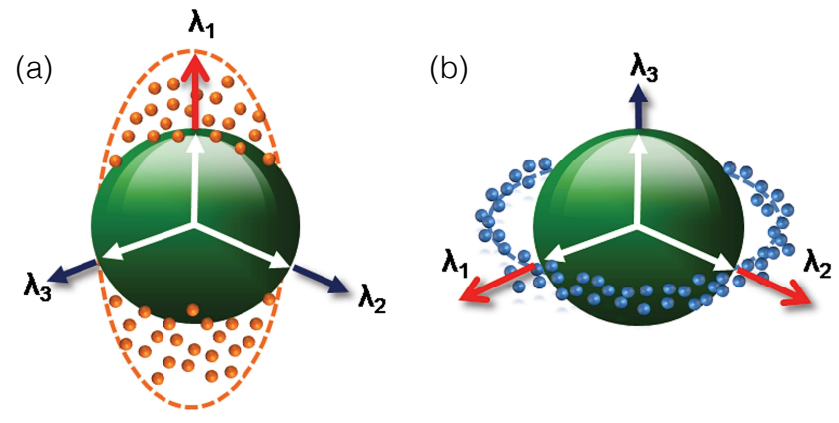

Figure 1. Distribution of axial orientation data on a spherical surface: (a) a clustered distribution and (b) a girdle distribution. In a clustered distribution, the axial orientation data have one large eigenvalue $\left(\lambda_{1}\right)$ and two small eigenvalues $\left(\lambda_{2}, \lambda_{3}\right)$. In contrast to this, the axial orientation data have one small eigenvalue $\left(\lambda_{3}\right)$ and two large eigenvalues $\left(\lambda_{1}, \lambda_{2}\right)$ in a girdle distribution.

scribing the level of irregularity on ground surface (Kim et al., 2012). The evaluation of the planarity is especially beneficial when large numbers of field data are acquired and compared which contain the directional characteristic of materials.

All cell-based (i.e., raster-based) calculations such as summation of elements in the orientation matrix by the moving window ( 3 by 3 ) and their geographical representations are augmented by the Spatial Analyst tool embedded in ArcGIS $^{\circledR}$. A cubic equation is employed to determine three eigenvalues. These are then normalized by $N$ total cells. Finally, planarity is introduced by a ratio of eigenvalues. Thresholds of each planarity are based on appropriate representation of characteristics of different geomorphological units consisting the study area. These are major valleys, secondary tributaries, gently rolling surfaces, and smooth surfaces. High planarity may indicate a smooth ground surface that has a preferred direction, while low planarity may have a less preferred direction, describing a rough ground surface, and may reflect previous landslides that contain relevant features such as scarps, cracks, and displaced materials (McKean and Roering, 2004; Kasai et al., 2009). 


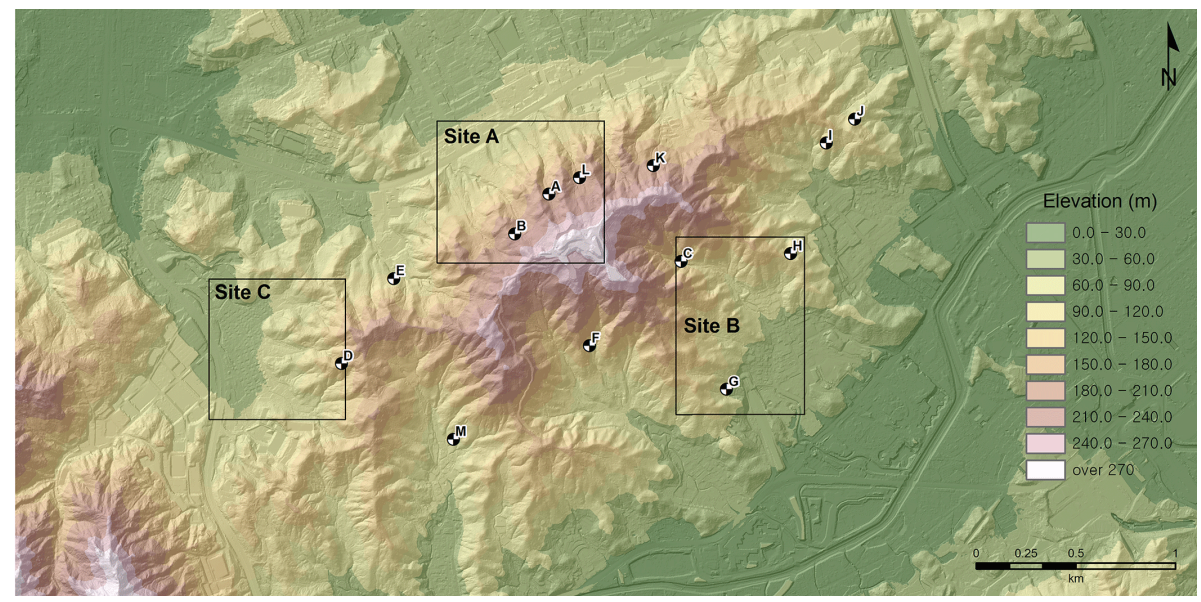

Figure 2. Location of the study area. Major landslide areas are also indicated. The position of each landslide area is calculated as a mean center for the individual landslide initiation zone: (A) Raemian Apartment, (B) Sindonga Apartment, (C) Hyunchon-maul, (D) Jeonwon-maul, (E) Bodeok-sa, (F) Songdong-maul, (G) Umyeonsan Tunnel, (H) Educational Broadcasting System buildings, (I) Gwanmun-sa, (J) Gangnam Church, (K) Seoul Arts Center, (L) Deokwoo-am, and (M) Dwit-gol. Areas outlined by black rectangles are shown in Figs. 10 to 12 . The geographic coordinates of the landslide area A are 37.474013 (latitude) and 127.006552 (longitude) in decimal degrees.

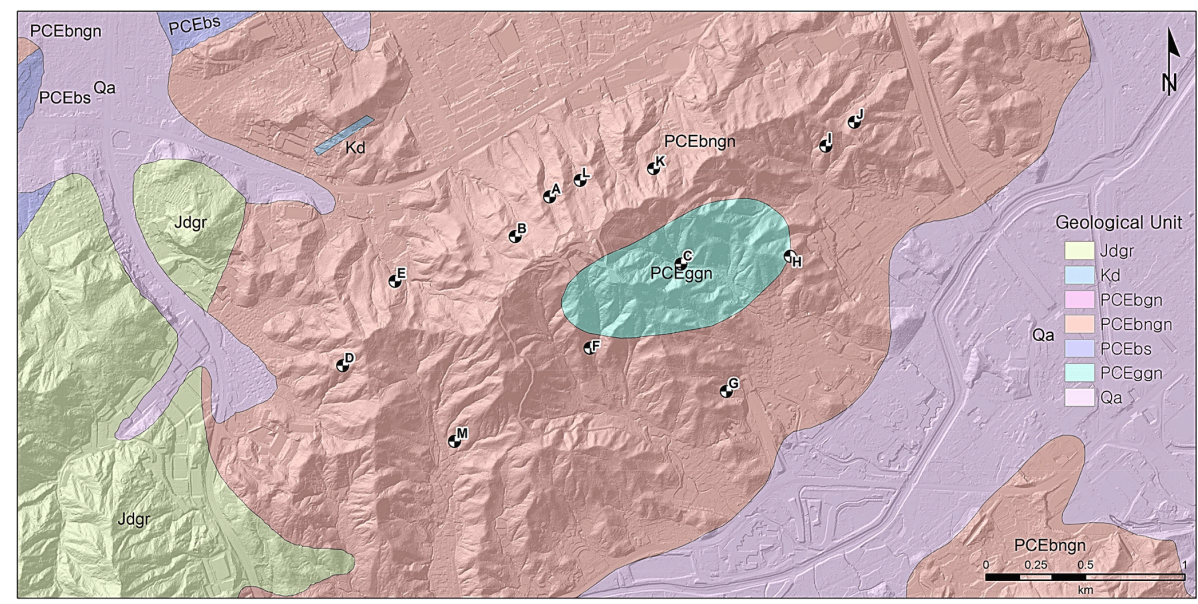

Figure 3. Geological map of the study area. Major landslide areas described in Fig. 2 are also shown. Representative geological units are: Jdgr (Jurassic Daebo granite), Kd (dikes), PCEbngn (pre-Cambrian era banded biotite gneiss), PCEbs (pre-Cambrian era biotite schist), PCEggn (pre-Cambrian era granitic gneiss), and Qa (Quaternary alluvium). All geological information are based on Kim and Hong (Kim and Hong, 1975) and Hong and Lee (Hong and Lee, 1982).

\section{Overview of the study area}

Mt. Umyeon, located south of Seoul Metropolitan City, Republic of Korea, is a part of major mountains traversing the southern part of Seoul in the north-northeast direction (Fig. 2). It has relatively low hilly reliefs which consists of a variety of gneisses from tectonic movements and weathering processes (Jeong et al., 2011). Major geological characteristic in the study area are dominated by the biotite banded gneiss and small portions are covered by augen gneiss, granitic gneiss, leucocratic gneiss, and fine-grained gneiss (Hong and Lee, 1982). Due to characteristics of gneisses such as severe weathering and multiple faults and geomor- phological defects such as many trails and military bases, the study area would have a high susceptibility to landslides. Figure 3 described distinct geological aspects of the study area.

The 2011 landslide disasters in the study area were initiated on 27 July 2011. Major landslide areas, which are indicated in Fig. 2, are (a) Raemian and Sindonga Apartments (Site A), (b) Jeonwon-maul (Site B), and (c) Hyungchonmaul (Site C). Table 2 summarizes general information on all landslide initiation zones, and detailed descriptions of individual sites are given in the following sections.

The procedure to identify a geomorphological feature using planarity is performed as follows. First, the DEM of 1 by $1 \mathrm{~m}$ spatial resolution is used for the calculation. It is taken 
Table 2. Landslides occurred on Mt. Umyeon in 2011. Each landslide area denoted by capital alphabet is also described in Fig. 2. Data are modified from Yoo et al. (2014). Cases being considered in this study (Sites A to C) are indicated in the column of the representative area name.

\begin{tabular}{llrrrr}
\hline \multirow{2}{*}{ ID } & Representative area name & \multicolumn{3}{c}{ Individual initiation zone } \\
\cline { 3 - 6 } & & $\begin{array}{r}\text { No. of } \\
\text { landslide }\end{array}$ & $\begin{array}{r}\text { Type of } \\
\text { landslide* }\end{array}$ & $\begin{array}{r}\text { Avg. slope } \\
\text { (Degree) }\end{array}$ & $\begin{array}{r}\text { Avg. volume } \\
\left(\mathrm{m}^{3}\right)\end{array}$ \\
\hline A & Raemian, Imgwang Apartments (Site A) & 6 & OD & 36.5 & 936.4 \\
B & Sindonga Apartment (Site A) & 3 & OD & 26 & 105.0 \\
C & Hyungchon-maul (Site B) & 30 & CD & 34 & 75.4 \\
D & Jeonwon-maul (Site C) & 22 & CD & 27 & 62.9 \\
E & Bodeok-sa & 14 & OD & 26 & 86.7 \\
F & Songdong-maul & 18 & CD & 36 & 182.0 \\
G & Umyeonsan Tunnel & 2 & CD & 29 & 129.3 \\
H & Educational Broadcasting System buildings & 3 & CD & 29 & 70.2 \\
I & Gwanmun-sa & 5 & CD & 31.5 & 90.9 \\
J & Gangnam Church & 11 & CD & 37 & 94.9 \\
K & Seoul Arts Center & 15 & OD & 37.3 & 207.3 \\
L & Deokwoo-am & 5 & OD & 35 & 98.7 \\
M & Dwit-gol & 16 & CD & 30.5 & 64.2 \\
\hline \multicolumn{2}{r}{ Total } & 150 & & & \\
\hline
\end{tabular}

* Evans (1982); OD: open slope debris flow; CD: channelized debris flow.

from the 2009 LiDAR data set (before landslides). Direction cosines are then calculated from the slope and aspect values. Each element of the orientation matrix shown in Eq. (2) is then represented by these direction cosines.

\subsection{Site A (Raemian and Sindonga Apartments)}

Site A is located in the north of Mt. Umyeon and was affected by two major landslides at different times. The first landslide began at 08:40 LT and the second one occurred at 10:00 LT on 27 July 2011. Both started their movement around summit areas of the mountain and flowed rapidly along the previous drainage channels. Finally, displaced materials peeled the ground surface in their routes, overflew the road, and destroyed the residential areas opposite to Mt. Umyeon (Fig. 4). This resulted in five casualties in total. Fast movement of displaced materials and existence of scars in slopes led us to classify those landslides as open slope debris flows (Evans, 1982; Hungr et al., 2014).

The elevation of major initiation and deposition zones are around $260 \mathrm{~m}$ and up to $80 \mathrm{~m}$, respectively. This leads to the significant vertical elevation difference of $180 \mathrm{~m}$. The largest trace of the major debris flows is about $620 \mathrm{~m}$ and their cross sections showed a gentler descending channel gradient from around 40 to $10^{\circ}$ (Yoo et al., 2014). Also, there was no evidence that displaced materials were preserved in the deposition zone, which may cause the catastrophic impact on residential areas across the landslides. The average depth of the surface erosion along the landslide profile was $1.6 \mathrm{~m}$ and a maximum depth of $4 \mathrm{~m}$ was observed at $320 \mathrm{~m}$ from the initiation zone. Based on the existence of thick colluvial layers, at least one historical landslide was recorded in this area and its debris was deposited on bedrock (Jeong et al., 2011).

\subsection{Site B (Hyungchon-maul)}

Site B is located on the southeast side of Mt. Umyeon and has a major gully and eight small tributaries over the area. Total 30 landslides started their movements on 27 July 2011, flooded into most residences within the site, and finally caused one casualty (Fig. 5). There was a reservoir located in the middle of the mountain that failed, overflowing water due to heavy rainfall intensity of over $85.5 \mathrm{~mm} \mathrm{~h}^{-1}$. Similar to other sites, the landslides are debris flows progressing along a major gully with the help of other small tributaries. These characteristics denoted them as channelized debris flow (Evans, 1982).

The elevation of initiation zone in this area is $250 \mathrm{~m}$ and the gradient is up to $40^{\circ}$. The bottom zone only has an elevation of $50 \mathrm{~m}$ and a gradient of $5^{\circ}$. The debris flow traveled about $980 \mathrm{~m}$ with $200 \mathrm{~m}$ of vertical elevation changes. The average erosion along the streambed was $1.5 \mathrm{~m}$ and a maximum erosion of $3.5 \mathrm{~m}$ was found at $180 \mathrm{~m}$ from the initiation zone (Yoo et al., 2014). There was a distinct interface between colluvial layer and bedrock. The composition of colluvium at this area is dominated by silt with pebble-sized gravel with up to $0.2 \mathrm{~m}$ diameter and piled $1 \mathrm{~m}$ high on average. Thick colluviums deposits, with an average of $1 \mathrm{~m}$, were often found in this area; up to $5 \mathrm{~m}$ of these was located where gullies merged each other (Jeong et al., 2011). 
(a)
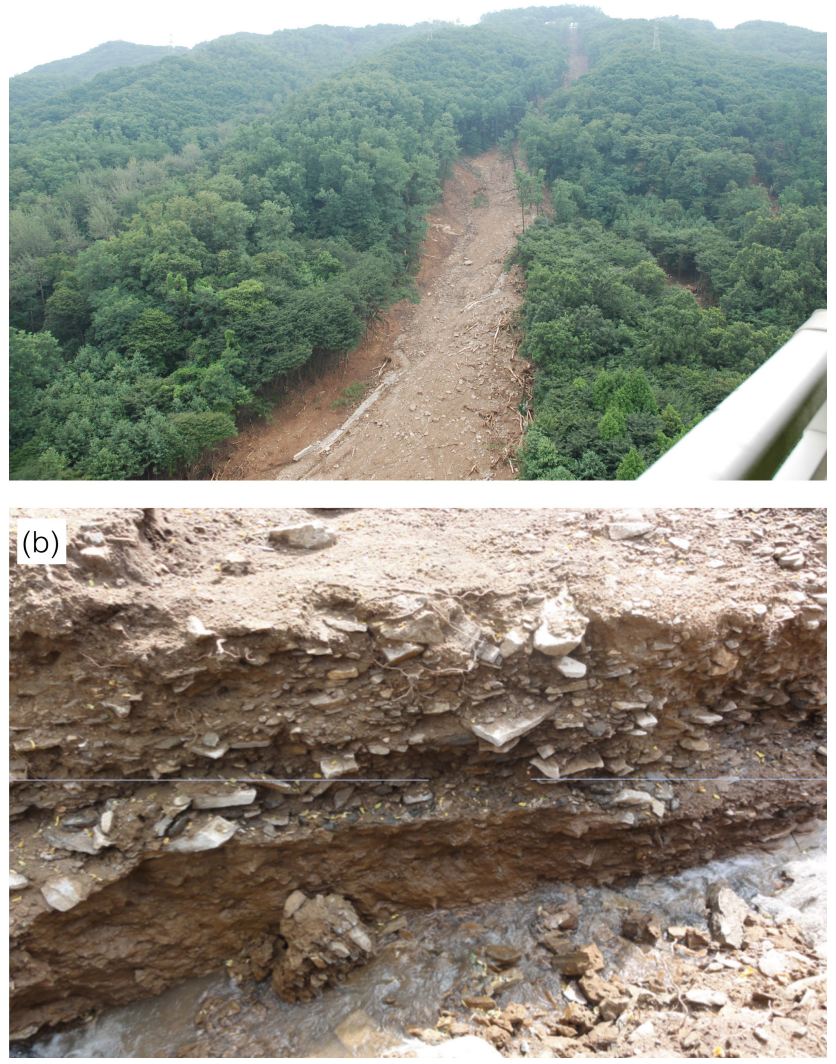

Figure 4. Landslides in Site A. (a) Overall trace of the landslide at Raemian A.P.T. area, looking southeast. Components of debris flows proposed by VanDine (1996) are identified. (b) Eroded colluvial layers observed at $320 \mathrm{~m}$ from the initiation zone.

\subsection{Site C (Jeonwon-maul)}

Located in the west part of Mt. Umyeon, landslides in Site C began in the morning of 27 July 2011 and resulted in six casualties (Fig. 6). Landslides can be classified as channelized debris flows because of their typical characteristics such as a fast downward movement of displaced materials along the existing gullies. The number of landslides in this site was reported at 22; their average slope angles at initiation and at transition zones were 27 and $15.6^{\circ}$, respectively (Yoo et al., 2014). These are consistent with what VanDine (1996) described about debris flow with typical slope angles of greater than 25 and $15^{\circ}$ for each individual zone. The average length of the transition zone was recorded as $454.4 \mathrm{~m}$ (Yoo et al., 2014).

Most foliations in gneiss were observed from the southeast direction opposite to slope gradient, and severe weathered strata were found up to $1 \mathrm{~m}$ thick. Silty soil and pebble-sized gravel of maximum $0.1 \mathrm{~m}$ diameter formed colluvial layers in this area (Jeong et al., 2011).
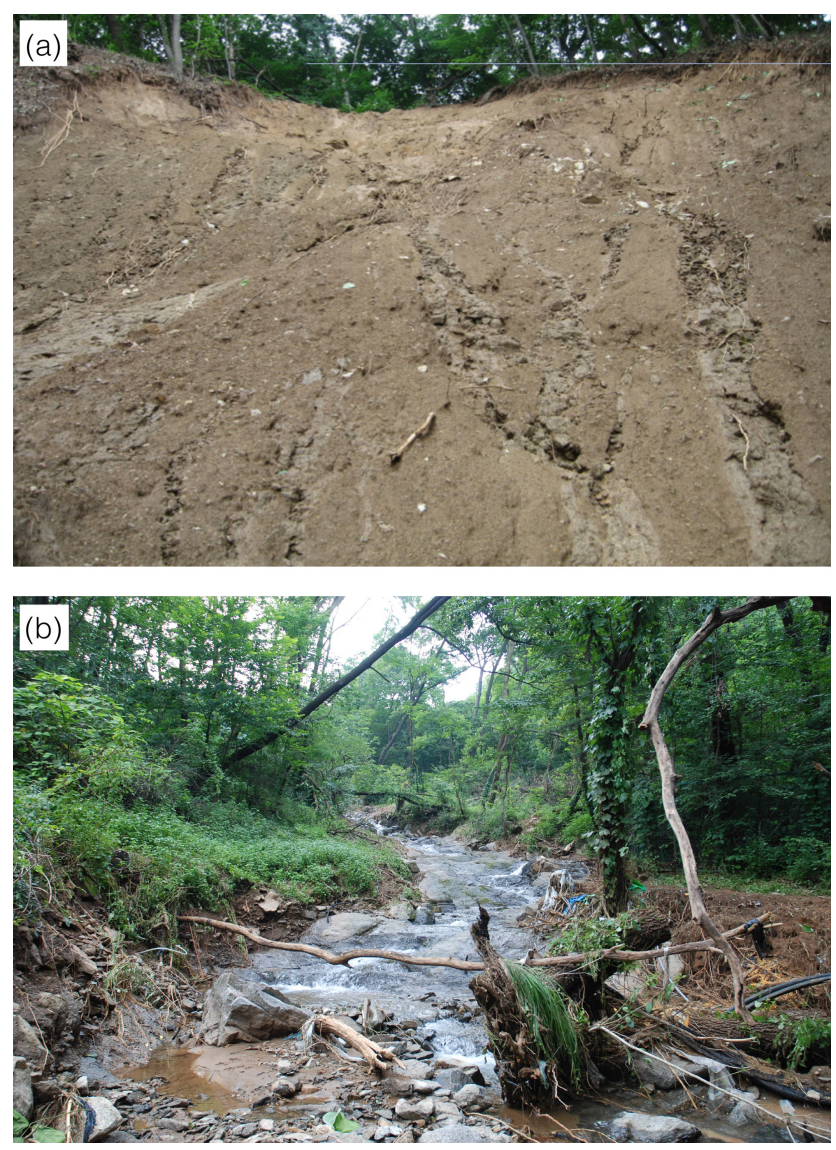

Figure 5. Landslides in Site B. (a) A closer look of the landslide initiation zone. A small volume of soil slid down along the smooth clayey surface which acts as a slickensided shear plane. (b) Upstream valley where debris flows were traced, looking northwest.

\subsection{Rainfall information}

The main cause of the landslides in the study area, even though the actual causal factor of this disastrous event is still unclear, is precipitation; it can be divided into two different domains based on the temporal variation: (a) antecedent rainfall and (b) daily rainfall. Firstly, an antecedent rainfall of $463.0 \mathrm{~mm}$ fell within 2 weeks prior to the landslide events. This made the ground surface fully or almost fully saturated. Secondly, a heavy daily rainfall amounting $342.5 \mathrm{~mm}$ fell into the study area. It took about $74 \%$ of antecedent rainfall. The first rainfall intensity which influenced the landslides was $62.5 \mathrm{~mm} \mathrm{~h}^{-1}$ (Fig. 7). Based on the rainfall records, the landslides in the study area may be initiated by a highintensity daily rainfall with the help of the saturated condition of the ground surface by long-term antecedent rainfall.

\section{Results and discussion}

In this study we employed a statistical analysis using axial orientation data to identify the geomorphological feature of 

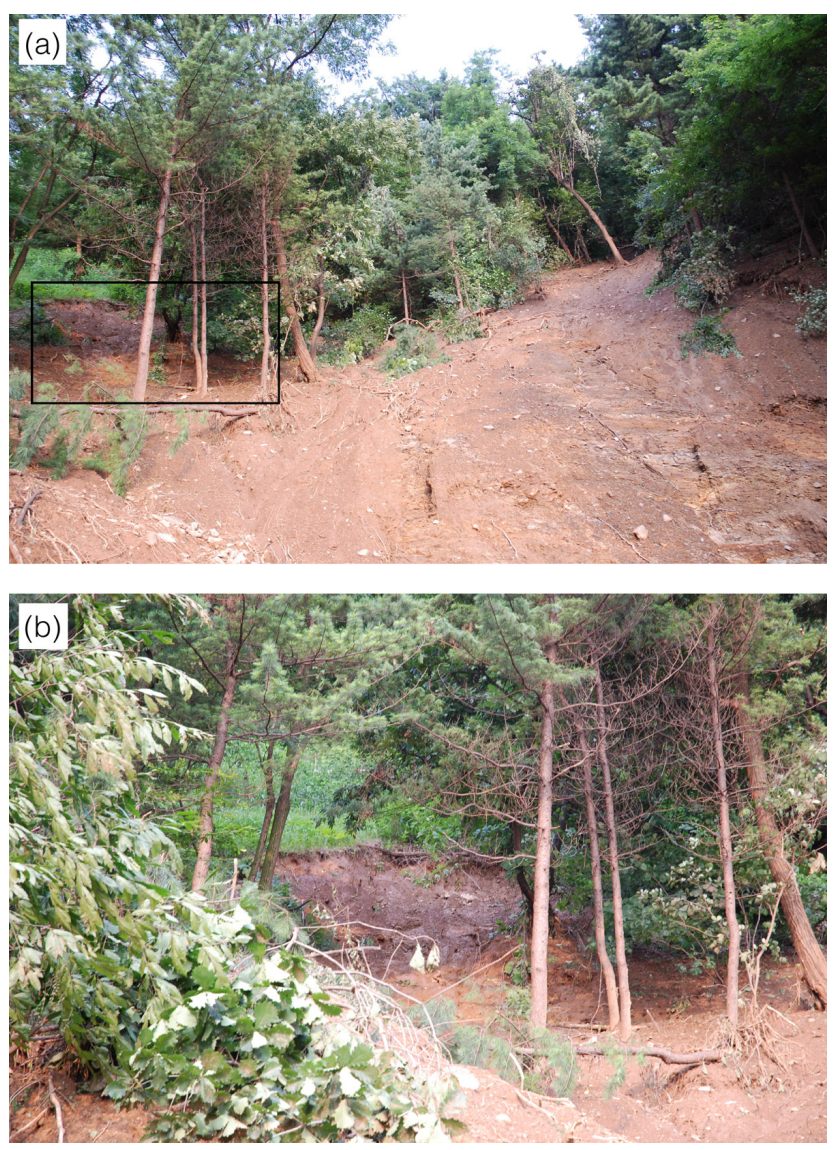

Figure 6. Landslides in Site C. (a) Landslide initiation zones, looking northeast. An area outlined by a black solid line presents a closer look of one of the initiation zones in slopes (b). (b) A closer look of the landslide initiation zone indicated in (a).

landslides. The main principle of this analysis is generating eigenvalues from axial orientation data and comparing their values. The planarity would tell the degree of irregularity on ground surface based on the ratios. The extent of the area for analysis is defined by the LiDAR data set acquired in 2009 before landslides occurred. The topographic overview of the study area is shown in Fig. 2.

Figure 8 shows the spatial distribution obtained from the planarity over the study area. The distribution is delimited to steep slope areas more than $15^{\circ}$ in slope values (i.e., the effective study area) and planarity beyond this extent is ignored since it could not describe a natural topography but an anthropogenic effect on the considered ground profile. Based on the planarity analysis shown in Fig. 8, the lowest planarity (less than 3), defined by this study as "very rough" areas, can be found in major valleys, secondary tributaries, and upper mountain areas near the army base located on the summit and accounts for $0.9 \%$ of the total evaluated area. Results also indicate that the "moderately rough (planarity is less than 5 )" areas cover $14.3 \%$ of the effective study area and these are usually wrapping the "very rough" areas. However, "rel-

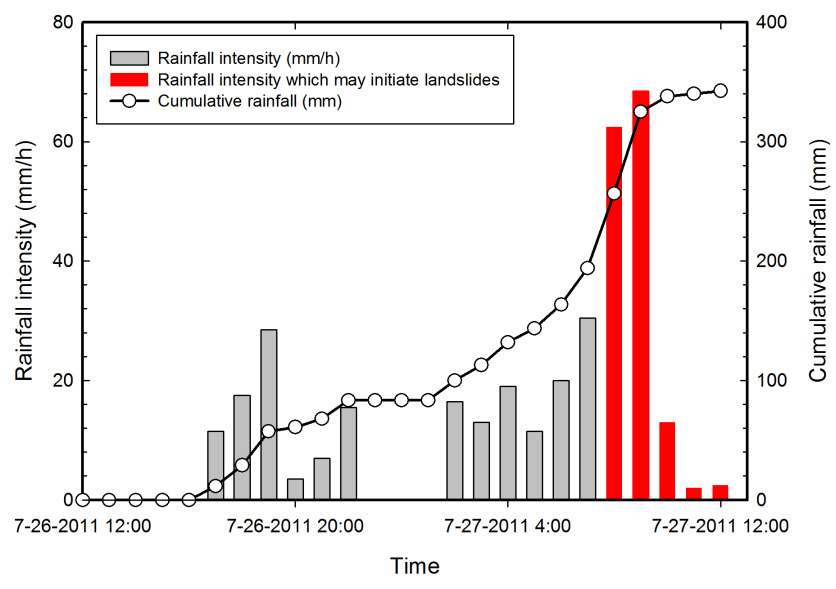

Figure 7. Temporal variation of precipitation from 26 to 27 July 2011. Vertical bars indicate the rainfall intensity and cumulative rainfall is shown by a black single line with circles. Some vertical bars in red represent the rainfall intensity which might cause landslides in the study area.

atively flat" areas, where the planarity is less than 7 , can be found on the most gentle slopes. The majority (about 50.6\%) of the evaluated area is included in this category. High planarity of less than 9 usually covers the other parts of gentle slopes. These areas, "mostly flat", take $28.4 \%$ of the evaluated study area. Finally, the "completely flat" areas, greater than 9, are concentrated on the few anthropogenic places that were constructed within or near the boundary of the mountain and are usually combined with "mostly flat" areas $(5.7 \%$ of the evaluated study area). Table 3 shows a detailed distribution of planarity on individual initiation zones. In this study we assumed the boundary of each initiation zone as a circle with a radius of $5 \mathrm{~m}$. Planarity is divided by same intervals noted in Fig. 8. Table 3 also describes designated slope values corresponding to the planarity.

A total 13 landslide initiation zones are analyzed based on the planarity method. Each landslide zone has a wide range of planarity, from 2.41 to 13.26 , and an average of 6 . This value is within the "very rough" and "moderately rough" categories and can be used as a threshold between stable and unstable domains. The unstable portion, i.e., less than 6 , of the planarity in all landslide initiation zones is $57 \%$ and ranges between 45 (C in Table 3) and 77\% (G in Table 3), respectively. This implies that landslide initiation zones have a lower planarity compared to other areas of consideration, which is based on two pre-defined conditions: (a) the boundary of landslide initiation zone delineated as a circle which ignores the real extent of the initiation zone and (b) the appropriate size of the moving window when the planarity is calculated. Tarolli et al. (2012) introduced a logical assumption for determining the moving window size for the channel network recognition in order to reduce the noise and noted that a proper window size is the critical element for extract- 
Table 3. Distribution of planarity and corresponding slope values in the study area.

\begin{tabular}{|c|c|c|c|c|c|c|c|c|c|c|c|c|}
\hline \multirow{2}{*}{ ID } & \multirow{2}{*}{ No. of landslides } & \multirow{2}{*}{ Area $\left(m^{2}\right)$} & \multicolumn{5}{|c|}{ Planarity* (\%) } & \multicolumn{5}{|c|}{ Slope (\%) } \\
\hline & & & $0-3$ & $3-5$ & $5-7$ & $7-9$ & over 9 & $10-20^{\circ}$ & $20-30^{\circ}$ & $30-40^{\circ}$ & $40-50^{\circ}$ & over $50^{\circ}$ \\
\hline A & 6 & 117.6 & 0.0 & 14.1 & 63.4 & 21.6 & 0.9 & 0.4 & 31.4 & 50.4 & 14.5 & 3.3 \\
\hline B & 3 & 58.8 & 0.9 & 17.6 & 56.7 & 14.1 & 10.7 & 0.9 & 33.0 & 57.9 & 6.0 & 2.2 \\
\hline $\mathrm{C}$ & 30 & 588 & 0.5 & 13.7 & 62.9 & 21.3 & 1.6 & 2.2 & 39.4 & 44.4 & 14.0 & 0.0 \\
\hline D & 22 & 431.2 & 1.2 & 16.0 & 60.0 & 22.0 & 0.8 & 1.9 & 50.6 & 42.8 & 4.5 & 0.2 \\
\hline E & 14 & 274.4 & 0.1 & 22.3 & 62.0 & 14.5 & 1.1 & 2.2 & 45.8 & 36.5 & 15.5 & 0.0 \\
\hline F & 18 & 352.8 & 0.7 & 20.9 & 54.8 & 21.7 & 1.9 & 3.0 & 42.5 & 46.1 & 7.7 & 0.7 \\
\hline G & 2 & 39.2 & 0.0 & 46.7 & 49.3 & 4.0 & 0.0 & 4.0 & 22.7 & 73.3 & 0.0 & 0.0 \\
\hline $\mathrm{H}$ & 3 & 58.8 & 0.0 & 5.6 & 79.5 & 14.1 & 0.9 & 0.9 & 50.4 & 48.7 & 0.0 & 0.0 \\
\hline I & 5 & 98 & 0.4 & 35.4 & 53.3 & 9.8 & 1.1 & 7.4 & 61.8 & 16.8 & 10.9 & 3.1 \\
\hline $\mathrm{J}$ & 11 & 215.6 & 0.0 & 19.9 & 52.1 & 25.7 & 2.3 & 4.1 & 48.4 & 44.7 & 2.8 & 0.0 \\
\hline $\mathrm{K}$ & 15 & 294 & 0.0 & 18.0 & 57.2 & 23.9 & 0.9 & 2.0 & 26.6 & 53.7 & 17.7 & 0.0 \\
\hline $\mathrm{L}$ & 5 & 98 & 0.0 & 24.7 & 67.2 & 8.1 & 0.0 & 0.5 & 27.3 & 47.0 & 15.7 & 9.5 \\
\hline M & 16 & 313.6 & 1.2 & 29.6 & 60.0 & 8.4 & 0.6 & 1.9 & 25.3 & 42.7 & 24.1 & 6.0 \\
\hline Total & tec & & & & & & & & & & & \\
\hline
\end{tabular}

* Min: 2.41, Max: 13.26, Average: 5.92 .

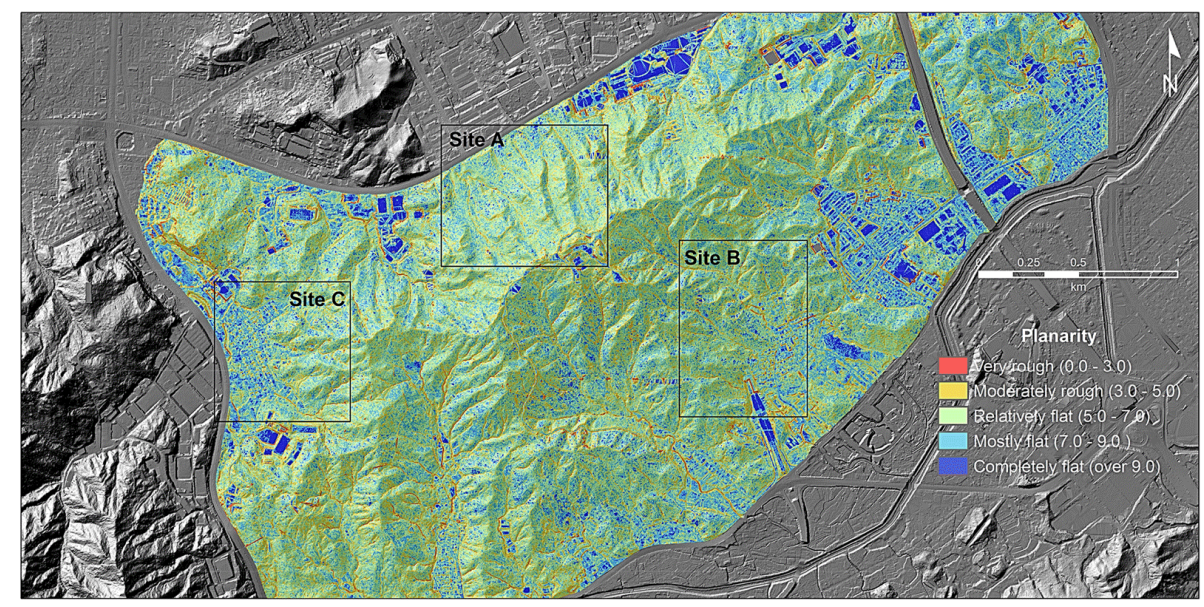

Figure 8. Spatial distribution of the planarity over the effective study area. Areas outlined by black rectangles are shown in Figs. 10 to 12.

ing appropriate geomorphological features. In our case, the moving window used in this study was 3 by 3 , which is relatively optimal for $1 \mathrm{~m}$ LiDAR-derived DEM. Nevertheless, some defects related to complex geomorphological structures may affect the performance of planarity.

In order to show the benefit of the planarity analysis in identifying the potential landslide hazards, the mean slope value of $19^{\circ}$ is employed since ignoring gentle slope areas would give a clear understanding of landslide hazards in the study area. Kim et al. (2012) noted that combining the planarity with slope can improve the capability of the landslide hazard assessment. Figure 9 illustrates the modified planarity where the individual cell is over the mean slope value. Finally, the modified planarity is implemented in representative landslide areas in 2011, i.e., Sites A to C, to evaluate its suitability as a indicator for the potential landslide hazard as- sessment. Figures 10 to 12 show examples of observations of landslides characteristics using planarity.

Figure 10a shows the aerial photo in Site A which was obtained before the landslide. There was a landslide in the relict state and might have been generated prior to 2011. The upstream part covered by forests can give a clue to the temporal variation since the landslide occurred. The modified planarity was draped on this area (Fig. 10b). Very rough areas are located in upper mountain areas that we believe are scarps from which the landslide might have been initiated. The other can be found along the valley bottom. The actual landslide in 2011 clearly showed that landslides began adjacent to very rough areas as determined by planarity (Fig. 10c). This consistency can also be found in Sites B and C (Figs. 11 and 12).

The reliability of the planarity as an indicator to identify the potential landslide hazard is evaluated by both bivariate 


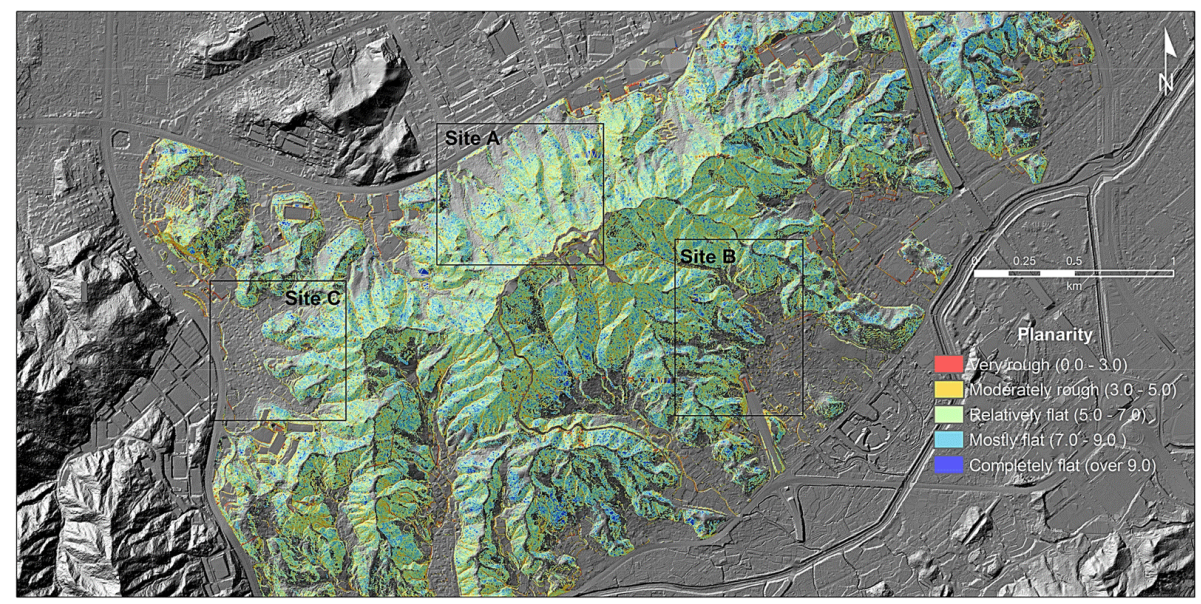

Figure 9. Spatial distribution of the modified planarity where the mean slope value is greater than $19^{\circ}$ over the effective study area. Areas outlined by black rectangles are shown in Figs. 10 to 12.

analysis, which correlates planarity with corresponding slope (Table 3 and Fig. 13), and multivariate analysis, which is based on the logistic regression model (Atkinson and Massari, 1998; Dai et al., 2002; Dai and Lee, 2003). By considering the bivariate analysis, results comparing the planarity with slope indicate that planarity shows a decreasing trend as slope increases. However, as Kim (2012) and Kim et al. (2012) noted, there is a degree of uncertainty in applying this relationship to the preliminary landslide hazard assessment. The uncertainty can be expressed as scatters in the plot when planarity is related to the slope and treated as noise. This is closely related to the site-specific geometry such as the presence of preferred directions which are perpendicular to the unit terrain rather than contributions to landslide causal factors.

The logistic regression model, which is applied to evaluate the reliability of the proposed method, forms a multivariate regression relationship between the dependent and several independent variables (Atkinson and Massari, 1998). Through logit transformation, this relationship can be converted into the ordinary linear regression model and this model represents a logistic regression of landslide causal factors and the corresponding probability of the presence or absence of landslides (Kim, 2012). A total of six landslide causal factors (slope, aspect, age of trees, dry unit weight of soil, presence of wildfire, and accumulated 3-day precipitation) are considered in this study (Yoo et al., 2014). Figure 14 shows a comparison of landslide hazard assessment based on two different methodologies. It indicates that there is a fairly good agreement in determining the high susceptibility of the preliminary landslide hazard (i.e., planarity less than 3 and landslide probability over 9) especially in the upper mountain areas. Other categories of the landslide hazards derived from both methodologies, however, represent some discrepancies in relating them. One possible explanation is the improper use of independent variables which are not delineating the circumstances of the study area. Therefore, it is necessary to carry out more investigations to find physical contributions of the planarity in order to make the potential landslide hazard assessment more comprehensive.

Even though there are various limitations which might come from the visual observation, the proposed methodology, the planarity analysis, can provide a useful framework to understand the initial state of landslides without any other conventional approach. It also gives fundamental data for the landslide inventory mapping, which is the initial form of the landslide hazard assessments. Combined with other physical considerations such as geotechnical monitoring for ongoing landslide movements, its feasibility as an indicator for the preliminary landslide hazard assessment can be enhanced and it can also suggest appropriate mitigation measures.

\section{Conclusions}

In this study we have delineated a possible application to identify the geomorphological feature mainly observed in the landslide area. Its usefulness for the preliminary landslide hazard assessment is also discussed. The planarity, based on the statistical analysis of axial orientation data, provides benefits when a geomorphological feature is identified by highresolution spatial data such as LiDAR-generated DEMs.

The spatial distribution of planarity would distinguish between stable and unstable domains in the study area especially in the landslide initiation zones. Within the study area the planarity has various portions of occupied areas and these roughly represent characteristics of different units consisting of slopes such as major valleys, secondary tributaries, gently rolling surfaces, and smooth surfaces. The three specific sites in the study areas also indicate that areas designated as "very rough" and "moderately rough" categories, in which the po- 

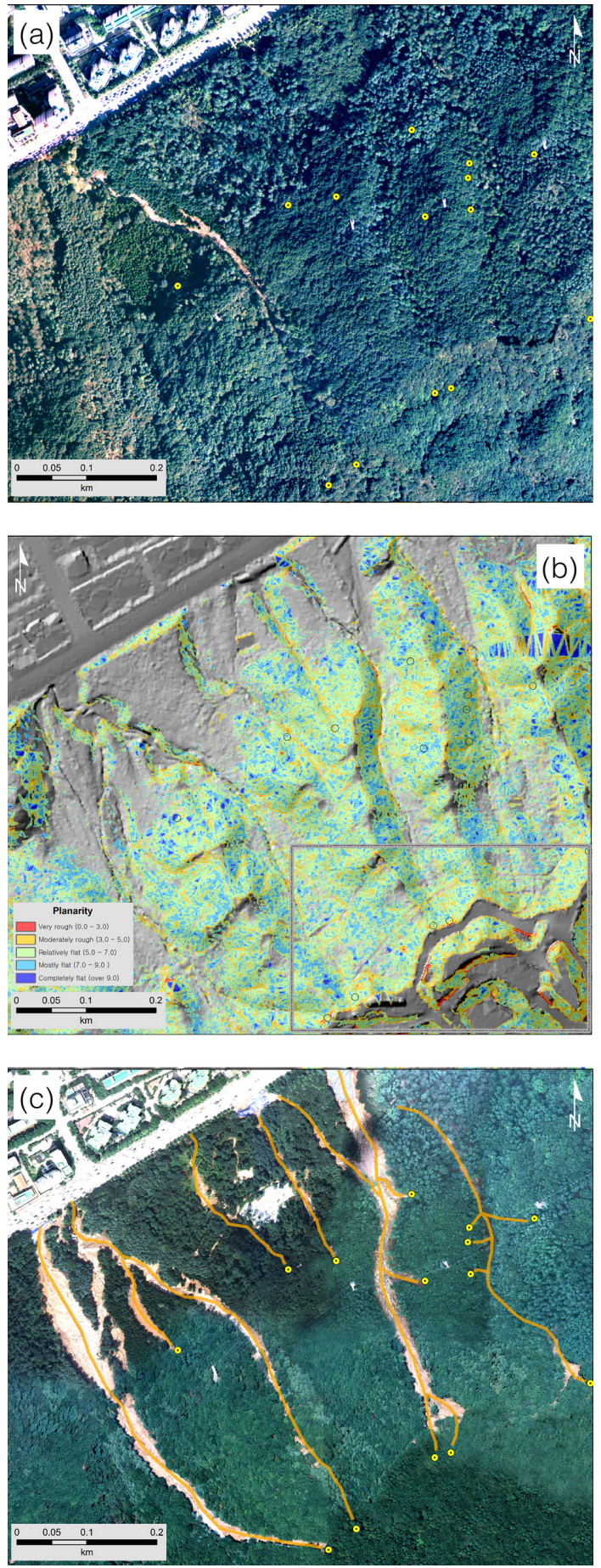

Figure 10. Feasibility evaluation of planarity in Site A. (a) Aerial photograph before the landslide (2009). Yellow circle with dot represents the landslide initiation zone. (b) Modified planarity: areas outlined by a black circle with a diameter of $5 \mathrm{~m}$ are the landslide initiation zones. A rectangle with a dotted line and a grey shade indicates a closer look at the representative area shown in Fig. 14. (c) Aerial photograph after the landslide (2011). Orange lines indicate observed landslide routes from the landslide initiation zones.
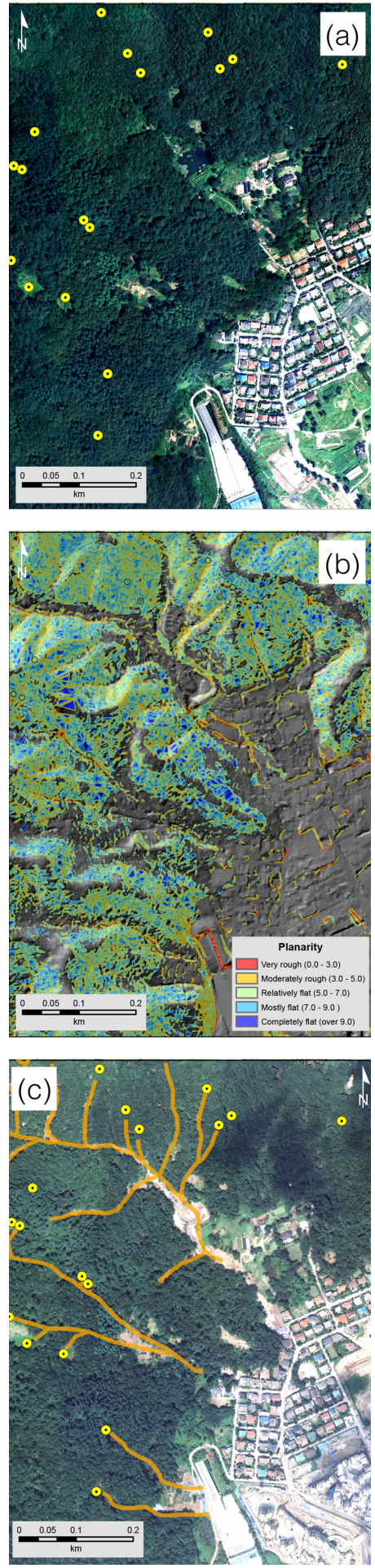

Figure 11. Feasibility evaluation of planarity in Site B. (a) Aerial photograph before the landslide (2009). Yellow circle with dot represents the landslide initiation zone. (b) Modified planarity: areas outlined by a black circle with a diameter of $5 \mathrm{~m}$ are the landslide initiation zones. (c) Aerial photograph after the landslide (2011). Orange lines indicate observed landslide routes from the landslide initiation zones. 

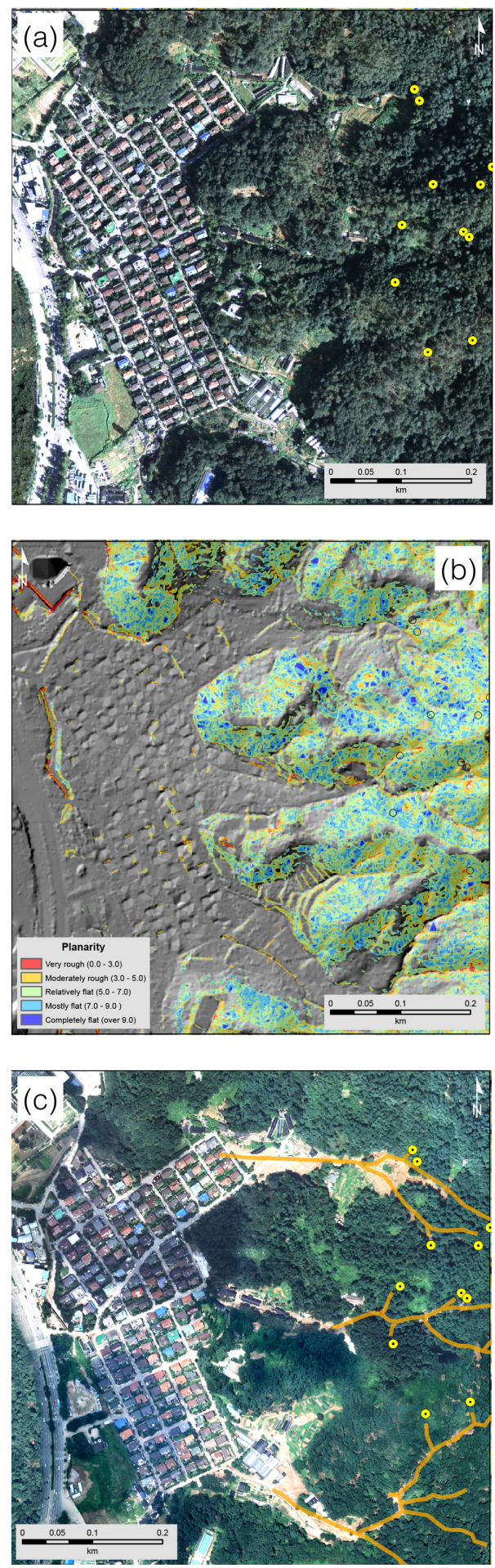

Figure 12. Feasibility evaluation of planarity in Site C. (a) Aerial photograph before the landslide (2009). Yellow circle with dot represents the landslide initiation zone. (b) Modified planarity: areas outlined by a black circle with a diameter of $5 \mathrm{~m}$ are the landslide initiation zones. (c) Aerial photograph after the landslide (2011). Orange lines indicate observed landslide routes from the landslide initiation zones.
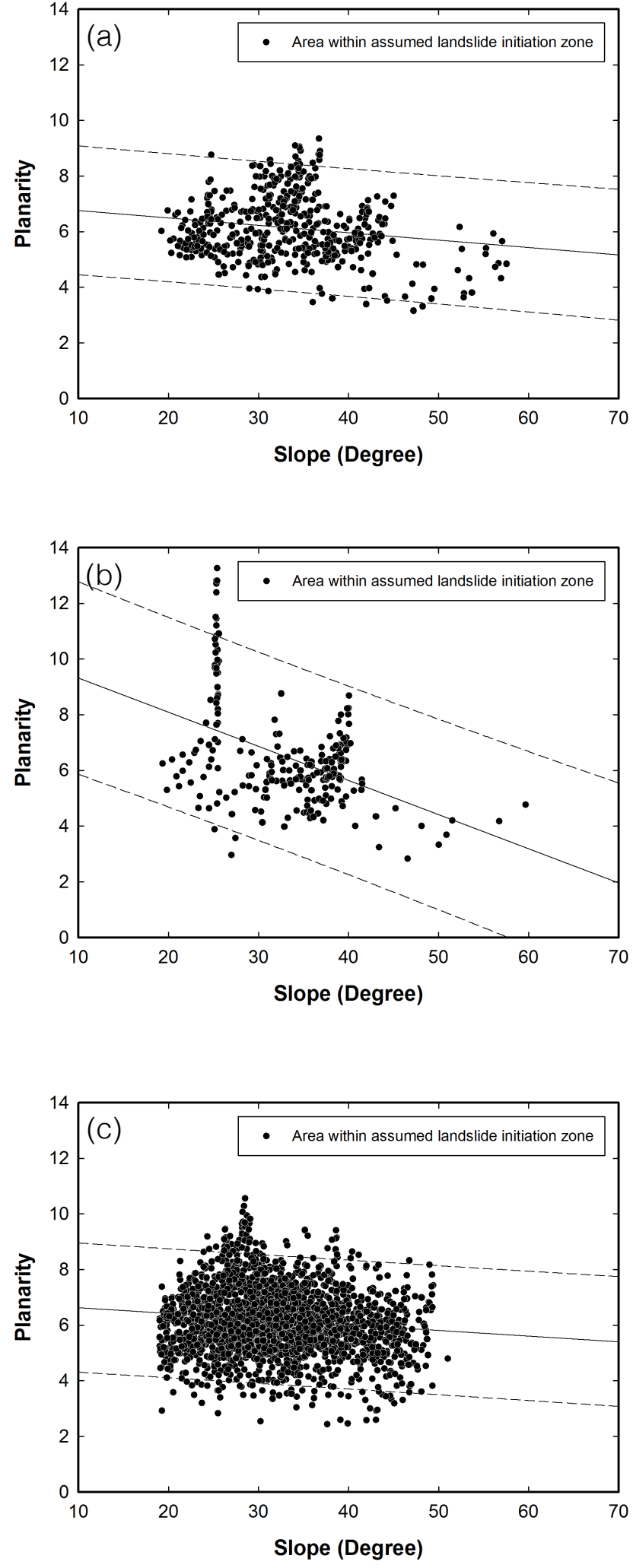

Figure 13. Relationships between planarity and slope in the study area. Values for slope and planarity are shown on the abscissa and ordinate, respectively. The linear regression is indicated by a black solid line and $95 \%$ of prediction intervals are also presented as black dotted lines. (a) Site A. (b) Site B. (c) Site C. 

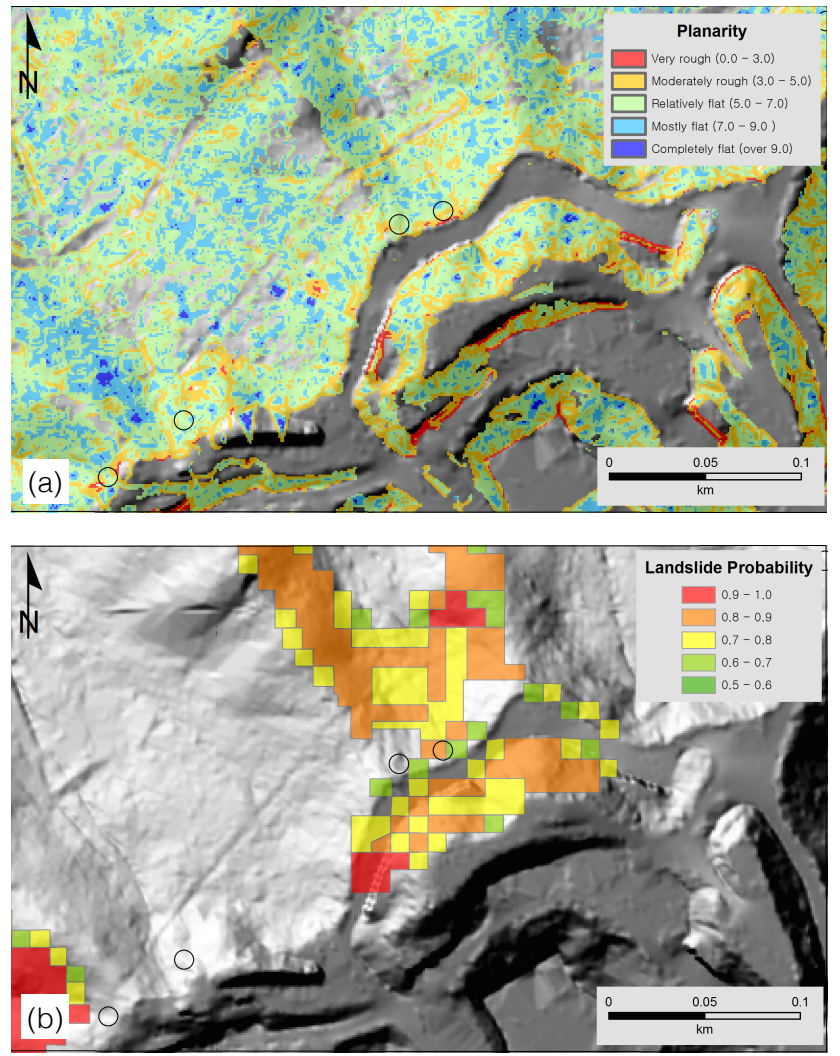

Figure 14. Evaluation of the planarity compared with the multivariate statistic carried out by Yoo et al. (2014). (a) Distribution of the planarity. The designated area is delineated in Fig. 10b. (b) The landslide hazard assessment is based on the logistic regression model.

tential landslide hazard is relatively high, are closely related to the actual landslide initiation zones.

Results are also useful in making the landslide inventory mapping without information on historical records of landslides. By combining other physical procedures, the landslide hazard assessment proposed in this study will promise a better understanding of landslides and their mechanisms and provide an enhanced methodology to evaluate their hazards and appropriate actions.

Acknowledgements. The authors are grateful to D. M. Cruden at the University of Alberta for constructive comments on earlier drafts of the paper. We also appreciate Areum Cha for assistance with illustrations and text processing. The manuscript was greatly improved by the comments of F. Catani and two anonymous reviewers.

Edited by: F. Catani

Reviewed by: two anonymous referees

\section{References}

Aleotti, P. and Chowdhury, R.: Landslide hazard assessment: summary review and new perspectives, Bull. Eng. Geol. Environ., 58, 21-44, 1999.

Atkinson, R. M. and Massari, R.: Generalised linear modelling of susceptibility to landsliding in the central Apennines, Italy, Comput. Geosci., 24, 373-385, 1998.

Catani, F., Farina, P., Moretti, S., Nico, G., and Strozzi, T.: On the application of SAR interferometry to geomorphological studies: Estimation of landform attributes and mass movements, Geomorphology, 66, 119-131, 2005.

Catani, F., Lagomarsino, D., Segoni, S., and Tofani, V.: Landslide susceptibility estimation by random forests technique: sensitivity and scaling issues, Nat. Hazards Earth Syst. Sci., 13, 2815-2831, doi:10.5194/nhess-13-2815-2013, 2013.

Dai, F. C. and Lee, C. F.: A spatiotemporal probabilistic modelling of storm-induced shallow landsliding using aerial photographs and logistic regression, Earth Surf. Proc. Land., 28, 527-545, 2003.

Dai, F. C., Lee, C. F., and Nagi, Y. Y.: Landslide risk assessment and management: an overview, Eng. Geol., 64, 65-87, 2002.

Delacourt, C., Allemand, P., Berthier, E., Raucoules, D., Casson, B., Grandjean, P., Pambrun, C., and Varel, E.: Remote-sensing techniques for analysing landslide kinematics: a review, Bull. Soc. Geol. France, 178, 89-100, 2007.

Evans, S. G.: Landslides and surficial deposits in urban areas of British Columbia: a review, Can. Geotech. J., 19, 269-288, 1982.

Glenn, N. F., Streutker, D. R., Chadwick, D. J., Thackray, G. D., and Dorsch, S. J.: Analysis of LiDAR-derived topographic information for characterizing and differentiating landslide morphology and activity, Geomorphology, 73, 131-148, 2006.

Grohmann, C. H., Smith, M. J., and Riccomini, C.: Surface roughness of topography: A multi-scale analysis of landform elements in Midland Valley, Scotland, in: Proceedings of Geomorphometry, 31 August-2 September, Zurich, Switzerland, 140-148, 2009.

Guzzetti, F., Carrara, A., Cardinali, M., and Reichenbach, P.: Landslide hazard evaluation: a review of current techniques and their application in a multi-scale study, Central Italy, Geomorphology, 31, 181-216, 1999.

Hong, S. H. and Lee, B. J.: Geological Map of Korea - map and explanatory description of Dungeon sheet, Korea Institute of Geoscience And Mineral Resources, Daejeon, Korea, 1-19, 1982.

Hungr, O., Leroueil, S., and Picarelli, L.: The Varnes classification of landslide types, an update, Landslides, 1, 167-194, 2014.

Jaboyedoff, M., Oppikofer, T., Abellán, A., Derron, M., Loye, A., Metzger, R., and Pedrazzini, A.: Use of LIDAR in landslide investigations: a review, Nat. Hazards, 61, 5-28, 2012.

Jeong, H., Choi, K., Shin, H., Kim, J., Bae, G., Han, M., Lee, S., Song, Y. S., Jang, S. C., Chae, B. G., Hwang, Y. C., Ahn, J. H., Yoo, B. O., and Kwon, O. I.: Investigation on cause and establishment of mitigation for Mt. Umyeon Landlsides - final report, Seoul Metropolitan Government, Seoul, Korea, p. 262, 2011.

Kaplan, V.: Using textural information for classification of remote sensing imagery, in: Proceedings of the International Symposium GIS Ostrava 2006, 23-25 January, Ostrava, Czech Republic, http://gis.vsb.cz/GISEngl/Conferences/GIS_Ova/GIS_Ova_ 2006/Proceedings/Referaty/kaplan.html (last access: 20 November 2014), 2006. 
Kasai, M., Ikeda, M., Asahina, T., and Fujisawa, K.: LiDAR-derived DEM evaluation of deep-seated landslides in a steep and rocky region of Japan, Geomorphology, 113, 57-69, 2009.

Kim, N. J. and Hong, S. H.: Geological map of Korea - map and explanatory description of Anyang sheet, Korea Institute of Geoscience And Mineral Resources, Daejeon, Korea, 1-20, 1975.

Kim, T. H.: Landslide hazard assessment, Town of Peace River, Alberta, PhD thesis, Department of Civil and Envrionmental Engineering, University of Alberta, Edmonton, 2012.

Kim, T. H., Cruden, D. M., and Martin, C. D.: Identification of geomorphological features of landslides using airborne laser altimetry, in: Proceedings of the 11th International Symposium on Landslides and 2nd North American Symposium on Landslides, 3-8 June, Banff, Alberta, 567-573, 2012.

Kimura, H. and Yamaguchi, Y.: Detection of landslide areas using satellite radar interferometry, Photogram. Eng. Remote Sens., 66, 337-344, 2000.

Mardia, K. V.: Statistics of directional data, Academic Press, London, 1972.

McKean, J. and Roering, J.: Objective landslide detection and surface morphology mapping using high-resolution airborne laser altimetry, Geomorphology, 57, 331-351, 2004.

Nefeslioglu, H., Gokceoglu, C., Sonmez, H., and Gorum, T.: Medium-scale hazard mapping for shallow landslide initiation: the Buyukkoy catchment area (Cayeli, Rize, Turkey), Landslides, 8, 459-483, 2011.

Pestrong, R.: Landslides - The descent of man, California Geol., 29, 147-151, 1976.

Sappington, J. M., Longshore, K. M., and Thompson, D. B.: Quantifying landscape ruggedness for animal habitat analysis: A case study using bighorn sheep in the Mojave Desert, J. Wildlife Manage., 71, 1419-1426, 2007.

Schulz, W. H.: Landslide susceptibility revealed by LIDAR imagery and historical records, Seattle, Washington, Eng. Geol., 89, 6787, 2007.
Schuster, R. L. and Highland, L. M.: Urban landslides: socioeconomic impacts and overview of mitigative strategies, the third Hans Cloos lecture, Bull. Eng. Geol. Environ., 66, 1-27, 2007.

Soeters, R. and van Westen, C.: Slope instability recognition, analysis and zonation, in: Landslides: Investigation and Mitigation (Special Report 247), edited by: Turner, A. and Schuster, R., Transportation Research Board, National Research Council, Washington, D.C., 129-177, 1996.

Tarolli, P., Sofia, G., and Fontana, G. D.: Geomorphic features extraction from high-resolution topography: landslide crowns and bank erosion, Nat. Hazards, 61, 65-83, 2012.

Teza, G., Pesci, A., Genevois, R., and Galaro, A.: Characterization of landslide ground surface kinematics from terrestrial laser scanning and strain field computation, Geomorphology, 97, 424437, 2008.

UNDP: Reducing disaster risk: A challenge for development, United Nations Development Programme, Bureau for Crisis Prevention and Recovery, One United Nations Plaza, New York, USA, 2004.

van Den Eeckhaut, M., Poesen, J., Verstraeten, G., Vanacker, V., Nyssen, J., Moeyersons, J., van Beek, L. P. H., and Vandekerckhove, L.: Use of LIDAR-derived images for mapping old landslides under forest, Earth Surf. Proc. Land., 32, 754-769, 2007.

VanDine, D. F.: Debris flow control structures for forest engineering, B. C. Ministry of Forests, Victoria, B. C., p. 68, 1996.

Watson, G. S.: The statistics of orientation data, J. Geol., 74, 786797, 1966.

Woodcock, N. H.: Specification of fabric shapes using an eigenvalue method, Geol. Soc. Am. Bull., 88, 1231-1236, 1977.

Woodcock, N. H. and Naylor, M. A.: Randomness testing in threedimensional rrientation data, J. Struct. Geol., 5, 539-548, 1983.

Yoo, K. Y., Won, J. S., and Yoo, Y. M.: Additional and complementary research on landslide causes in Mt. Umyeon - final report, Seoul Metropolitan Government, Seoul, Korea, p. 452, 2014. 